\title{
Collaborative entrepreneurship, diversity management, and entrepreneurial performance of small and medium scale firms in Nigeria
}

\author{
Obinna Christian Ojiaku ${ }^{1}$, Nkechi C. Ojiagu, ${ }^{2}$, Obianuju E. Agbasi ${ }^{3}$ \\ Department of Marketing, Nnamdi Azikiwe University, Awka, Anambra State ${ }^{1}$ \\ Department of Cooperative Economics \& Management, Nnamdi Azikiwe University, Awka, \\ Anambra State ${ }^{2,3}$

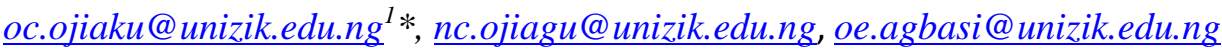

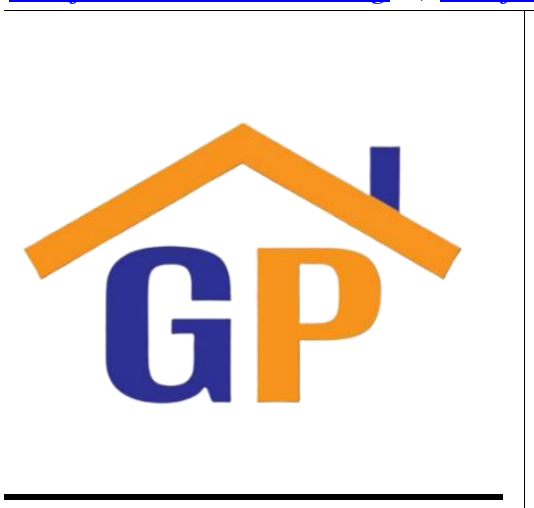

Article History

Received on 4 July 2020

$1^{\text {st }}$ Revision on 3 August 2020

$2^{\text {nd }}$ Revision on 6 August 2020

Accepted on 7 August 2020

\begin{abstract}
Purpose: This paper investigates the effects of collaborative entrepreneurship and diversity management on entrepreneurial performance.

Research methodology: A cross-section survey of 110 employees from the construction and auto-service SME in Nigeria was adopted, and multiple regression analysis via SPSS version 15 was used to analyze the hypothesized relationships.
\end{abstract}

Results: The result shows a statistically significant relationship for external collaborative entrepreneurship and diversity management on firm performance.

Limitations: The inability to collect data from all the major cosmopolitan cities in Nigeria where a larger pool of ethnicallydiverse workforce resides limits the generalizability of the finding.

Contribution: Entrepreneurs and small and medium scale enterprises in construction and auto works will find this work useful for effective collaboration.

Keywords: Entrepreneurship, Collaboration, Diversity management, Ethnicity, Performance, Nigeria

How to cite: Ojiaku, O. C., Ojiagu, N. C., Agbasi, O. E. (2020) Collaborative entrepreneurship, diversity management, and entrepreneurial performance of small and medium scale firms in Nigeria. International Journal of Financial, Accounting, and Management, 2(2), 131-144.

\section{Introduction}

Given the dynamics of the current business environment - usually characterized by highly competitive markets, changing consumer taste, and resource scarcity - creating sustainable economic value for customers and gaining competitive advantage has become more challenging for organizations than ever before. With the evidence to suggest better growth and profitability for entrepreneurial firms than non-entrepreneurial firms, businesses are increasingly becoming more entrepreneurial in their orientation (Rezazadeh \& Nobari, 2018). Entrepreneurial firms manifest through their ability to pursue opportunities without regard to the resources they currently control (Stevenson \& Jarillo, 1990). Accordingly, to gain competitive advantage, firms obtain needed resources by strategically collaborating externally with complementary firms, and fostering internal collaboration among its workforce. In order to induce or create opportunity for collaboration (Ahuja, 2000), firms engage a culturally-diverse workforce with specific ethnic-skills and by so doing, leverage on their cognitive resources through fostering and using collective creativity, and co-opting resources with significant others (Horwitz \& Horwitz, 2007; Yan \& Sorenson, 2006). In other words, businesses collaborate to access resources and competencies outside their reach to create economic value (Riberio-Soriano \& Urbano, 2009). 
Firms collaborate despite their competitiveness or otherwise, to address or overcome business challenges that may pose a threat to their survival (Ratten \& Ratten, 2014) or to take advantage of new opportunities in the business environment (Filion, 1999). This organizational behavior is called collaborative entrepreneurship (Riberio-Soriano \& Urbano, 2009). In this context, collaborative entrepreneurship is the process firms generate or exploit opportunities through partnering with people, businesses, or government establishments (Naude, Szirmai, \& Guedhuys, 2011; Ratten \& Ratten, 2014). While the focus of scholarly discussion on collaborative entrepreneurship has been for radical or incremental innovation, especially, among developed nations (Ahuja, 2000; Andresen, Lundberg, \& Wincent, 2014), this paper focuses on collaborative efforts among firms in developing countries. The innovative capacity in this context are those related to the discovery and exploitation of marketable opportunities, but not necessarily the introduction of new products.

Firms are entrepreneurial to the extent they can collaborate internally and/or externally to gain access to resources (Franco \& Pessoa, 2014). Through collaborative entrepreneurship, firms access resources in the form of social, technical, commercial capital (Ahuja, 2000), or human capital. These resources are, at best, harnessed through the development of team diversity and social networks (Franco \& Haase, 2013). The diversity among work teams in terms of age, gender, educational background and especially ethnicity, reduces risk aversion, makes varied ideas, skills and perspectives accessible, stimulates creativity, and problem-solving capability among team members and by extension enhances organizational performance (Bassett-Jones, 2005; Latimer 1998; Boone, Lokshin, Guenter, \& Belderbos, 2018). When ethnic diversity is polarized, it encourages the exclusion of talented and skilful team members ( benefits of collaborative efforts (Barnes-Mauthe et al., 2013). Hence, enterprises that successfully manage team diversity will foster collaborative entrepreneurship, and thus, promote creativity and effective decision-making (Bassett-Jones, 2005; Barnes-Mauthe et al., 2013).

However, despite the benefits of workforce diversity, and the opportunity to collaborate to access resources, scholarly discussion on collaborative entrepreneurship and management of team diversity is scant. Accordingly, Ratten and Ratten (2014), call for more research on collaboration along ethnic or geographical lines, especially for developing countries. Furthermore, Nyambegera (2002) posits that there is a paucity of research on the management of ethnic diversity among Sub-Sahara Africa countries. We address this gap and investigate the relationship between the management of ethnic diversity and collaboration entrepreneurship drawing from the resource-based theory, dynamiccapability theory, and categorization-information elaboration model (CEM). We further ascertain the extent this relationship affects organizational performance. We, therefore, argue that, given the diversity of skillset common among ethnic groups in Sub-Sahara Africa, firms that recruit team members from this diversity can harness their talents and skills by promoting collective entrepreneurship and inter-firm alliances to achieve organizational objectives. We, therefore, ask: to what extent does diversity management enhance entrepreneurial performance? What are the effects of internal and external collaborative entrepreneurship on firm performance?

To the best of our knowledge, we make the following novel contribution to the entrepreneurship and diversity management literature. First, we adopt an interdisciplinary approach by integrating collaborative entrepreneurship from the strategic management and entrepreneurship literature and diversity management from the human resource management literature to understand the entrepreneurial performance of SMEs in an emerging country context. Second, while prior research examined collaboration in the context of product innovation, we applied the concept to investigate market innovation in the service sector. In other words, we examined how firms collaborate internally and externally to meet market needs. Finally, the present study makes a novel contribution by investigating collaborative entrepreneurship, ethnic diversity management, and entrepreneurial performance of SMEs in a typical sub-Saharan African context. This perspective is essential because as Umenzinwa (2012) argued, ethnicity is a basic problem in Nigeria and a cog in the nation's developmental strides. 


\section{Literature review}

\subsection{Theoretical background}

Collaborative entrepreneurship and diversity management are two concepts with firm-level resources (i.e., human capital) as their unit of analysis. While collaborative entrepreneurship involves alliances between entrepreneurs, entrepreneurial firms, and within an enterprise work team to create, discover, and exploit opportunities (Ratten, 2014), Diversity management preaches the strategic effort to recruit, train, develop competences, and foster effective working relationship among a workforce with diverse social identities. Accordingly, this study draws from the theoretical perspectives of resourcebased theory, dynamic capability theory, and categorization-elaboration model to investigate the effects of collaborative entrepreneurship, diversity management, and entrepreneurial performance. Proponents of the RBT argue that the resources and capabilities of the firm provide the foundation for a firm's strategy and a source of competitive advantage (Ahuja, 2000, Wernerfelt, 1984). Firms thrive to access resources that could give them a competitive edge over their closest rivals (Ahuja, 2000, Galaskiewicz \& Zaheer, 1999; Wernerfelt, 1984). These resource-bundles are heterogeneous across firms and include employees' competences. The attribute of resources held by firms can contribute to and determine their level of performance (Yang \& Konrad, 2011). These resources are rare, valuable, and imitable and can be in the form of diversity in human capital which provides a diversity of information, knowledge, perspectives, talents, and the development of effective working relationships among a diverse workforce (Yang \& Konrad, 2011). The RBT also offers an explanation for firms' motivation to collaborate to access resources that they do not currently control (Kusa, 2017), hence, it is a basic condition for entrepreneurship (Alvarez \& Busenitz, 2001). Therefore, the RBT provides a theoretical base for collaborative entrepreneurship and entrepreneurial performance in this study.

Similarly, the dynamic capabilities theory offers a theoretical base for internal and external collaboration. The dynamic capabilities theory emphasizes the significance of internal and external competencies in capturing new markets and responding to changes in the environment (Teece, 2014). It focuses on the capabilities that enable firms to create or capture value by responding to changing market circumstances (Teece \& Pisano, 1994; Roundy \& Fayard, 2018). According to Teece, Pisano, and Shuen (1997), dynamic capabilities refer to a 'firm's ability to integrate, build, and reconfigure internal and external competences to capture value in dynamic environments. It involves sensing, seizing, and transforming processes necessary to sustain competitive advantage as technology and market changes. Teece (2007) adds that these processes must cut across the hierarchies of the organization to include managers, supervisors, experts, and line workers. Dynamic capabilities can be seen as an extension of the resource-based view where the firm is conceived as a collection of resources, e.g. technologies, skills, and knowledge-based resources (Nielsen, 2006).

In addition, the positive information processing of the categorization-elaboration model offers theoretical explanations for the diversity of the workforce and the need for firms to manage such diversity for competitive advantage. The categorization-elaboration model integrates both positive (information processing) and negative (social categorization) views on the impact of diversity on team outcomes (Van Knippenberg, De Dreu, \& Homan, 2004). The model posits that each type of diversity can have a positive and negative effect and therefore, it is not the diversity but the diversity context that drives the positive or negative consequences (Ayub \& Jehn, 2018). Specifically, the positive information processing perspective argues that the heterogeneity of multicultural teams offers diverse perspectives, skills, and knowledge that help group performance (Ayub \& Jehn, 2018; Wang, Cheng, Chen, \& Leung, 2019). We draw on the theory to explain diversity management in this study.

\subsection{Conceptual framework and hypotheses}

\subsubsection{Collaborative entrepreneurship}

Since entrepreneurship is typically defined by the creation of economic value, either through the discovery and exploitation of marketable opportunities, or the introduction of new products (Shane \& Venkataraman, 2000). Then, the proactiveness to form partnerships externally or to harness the skills among work teams internally, is an important part of entrepreneurial behavior (Ratten \& Ratten, 2014; Franco \& Pessoa, 2013). Collaborative entrepreneurship is also known with such alias as strategic alliances, inter-firm alliances or linkages, joint ventures, or partnerships. It is the creation of 
something of economic value arising out of new, jointly created ideas that emerge from the sharing of information and knowledge (Gupta \& Govindarajan, 2000 cited in Franco \& Haase 2013, pg. 681). According to Filion (1999), the essence of collaborative entrepreneurship is to take advantage of new opportunities in the business environment. Collaborative entrepreneurship can occur internally when work teams integrate their skills to create a whole that is larger than the sum of their contributions (Yan \& Sorenson, 2006); or externally through inter-firm cooperation to enhance entrepreneurial performance (Rezazadeh \& Nobari, 2018). These capabilities are referred to as collective entrepreneurship and collaborative entrepreneurship respectively (Ribeiro-Soriano \& Urbano, 2009).

The rationale for collaboration among and within firms include: to access new markets and technologies, risk reduction, and improve competitiveness, exchange knowledge/technology, and expertise enhancement (Lassen, Laugen, \& Middel, 2008; Rezazadeh \& Nobari, 2018). Collaboration has helped to improve decision-making within and between firms, accelerate information sharing, and further escalate commitment to entrepreneurial behavior (Diaz-Foncea \& Marcuello, 2013). RibeiroSoriano and Urbano (2009) add that collaboration improves access to resources, organizational flexibility and agility, trust-building and networking capability, and proactive communication with market participants (Rezazadeh \& Nobari, 2018). Studies have shown that when firms collaborate, they tend to develop and absorb new technology (Ahuja, 2000), withstand environmental shocks (Miner, Amburgey, \& Stearns, 1990), and improve entrepreneurial performance (Franco \& Haase, 2013). Accordingly, we hypothesize as follows:

\section{H1: Internal and external collaboration has a positive and significant influence on the entrepreneurial performance of SMEs.}

\subsubsection{Diversity management}

In most of Sub-Sahara Africa countries, the composition of the workforce usually consists of people from diverse ethnic backgrounds. However, when this ethnic configuration is polarized, it makes getting the best from people difficult, especially as specific skills and competencies reside within people of diverse ethnicity. Anecdotally, some of the best-skilled labour in mason are the Togolese and Ivorien of West Africa. Similarly, some of the best-skilled labour in tailoring are the Ghanaians or the Aba boys of Nigeria, and some of the best automobile mechanics are the Yorubas and Benin from Nigeria. These and many more skills can be found in specific ethnic nationalities, suggesting the need for diversity management in the work environment.

Diversity management is when organizations provide an enabling environment for every member of its work team to perform to his or her potential (Olsen \& Martins, 2012). It is the systematic and planned commitment on the part of organizations to recruit and retain employees with diverse backgrounds and abilities (Bassett-Jones, 2005). Generally, diversity encompasses a range of differences in ethnicity, gender, religion, ability, language, or lifestyle (Kossek \& Lobel, 1996). In this regard, it is the strategic option to recruit from a diversity of ethnicity based on their specific ethnicskills and providing an enabling environment for equal opportunity for all.

The ethnicity component constitutes a primary dimension of diversity because of the sense of identity that it engenders (Nyambegera, 2002). Ethnicity among social actors results from a lack of cooperation and the presence of competition. Usually, characterized by social and economic discrimination capable of creating a much stronger divide among people (Nnoli, 1995). These can affect the level and quality of information individuals receive, the attitude and belief they form, and the interactions they experience (Barnes-Mauthe et al., 2013). Fostering diversity in work teams through an inclusive environment can lead to competitive advantage (Nyambegera, 2002). Such diversity makes accessible the full creativity and talents of diverse work teams, varied skills and ideas, foster constructive debate, stimulates creativity and effective decision making, and improved performance (Sabharwal, 2014; Boone et al., 2018). Empirical evidence has shown a positive relationship between diversity management and firm performance (Cooke \& Saini, 2010; Pitts, 2009). Similarly, Boone et al. (2018) find that diversity management enhances corporative entrepreneurship depending on the inequality in social relationships. Therefore, we hypothesize thus: 
H2: Diversity management has a positive and significant influence on the entrepreneurial performance of SMEs.

\subsubsection{Diversity management and collaborative entrepreneurship}

The ethnic-diversity of a firm's workforce provides it with varied skills and competence to drive entrepreneurship. For firms to effectively collaborate to take-risk, proactively respond to market opportunities, and continuously spur innovativeness and creativity, it would need to draw from the strength of the heterogeneity of its workforce, which expressly draws on the diversity of ethnic perspective (McLeod, Lobel, \& Cox, 1996). Ethnic diversity, therefore, is a source of cognitive resources that allows collaboration to take place. In fact, Rodríguez-Pose and Hardy (2015) argued that ethnic diversity, represented with a common background in education and culture, is the primary driver of entrepreneurship. When work teams consist of people with varied ethnic skills, knowledge, and expertise, more creative ideas and innovations are birth, and team performance improves (Ayub \& Jehn, 2018). Furthermore, the perspective from integration and learning suggested that the insights, experiences, and competencies employees develop as members of a diverse ethnic groups are potentially valuable resources work teams can harness for better performance (Kochan et al., 2003).

In most of Sub-Sahara Africa, it is common to find a workforce from a similar ethnic background possessing a similar skillset. It is this trajectory of skill development among people of the same ethnicity that we refer to as ethnic-skill (Friberg \& Midtbøen, 2018; Rodríguez-Pose \& Hardy, 2015). Entrepreneurial firms, especially in construction and fabricating industries, strategically employ people with ethnic skills, and by managing the diversity in the work environment promotes collaborative entrepreneurship. In this case, the heterogeneity of the work-teams provides a pool of skills, talents, and experience to exploit market opportunities and introduce new products and services. This collaborative entrepreneurship behaviour is typically found in the automobile, fashion, and construction and fabricating sector of most Sub-Sahara economies. For example, a fashion entrepreneur could strategically employ tailors form Senegal or Togo for their perceived comparative competencies in garment making. In line with this reasoning, Wang et al. (2019) found cultural diversity to be positively related to team creativity/innovation. Also, Boone et al. (2018) found that top management team nationality diversity fosters corporate entrepreneurship in terms of technology diversity, technology alliances, corporate venturing, and technology-based mergers and acquisition. Therefore we hypothesize thus:

\section{H3: Diversity management has a positive and significant influence on collaborative entrepreneurship.}

\subsubsection{Entrepreneurial Performance}

The concept of performance has been both elusive and challenging to define (Pinho \& de Sa, 2014). Ely and Thomas (2001) describe performance as the execution or accomplishment of work, tasks, or goals to a certain level of desired satisfaction. It is the extent organizations attain their goals and objectives exhibited through its employees' task accomplishment as well as the quality of the task completed within a specific business period compared against set targets (Emejulu, Obianuju, Nosike, 2020). Entrepreneurial performance entails using available opportunities to grow business ideas or to achieve entrepreneurial goals (Sebikari, 2019). It reflects the extent a firm can accept risks and be innovative or competitively aggressive (Hayton, 2003; Lumpkin \& Dess, 1996). Nyambegera, (2002) contends that entrepreneurial performance depends more on the effective utilization of human capital rather than on physical capital. This is because technological and other material resources, in spite of their importance, are generated by the industrious and creative efforts of people, and it is their ingenuity that ensures that these resources are effectively deployed.

So far, there is no consensus on the indices to measure performance. However, the literature identified subjective measures and objective measures. Subject measures are nonfinancial measures that assess the growth and success of an enterprise from the point-of-view of the owners or workers, and the attainment of specific entrepreneurial goals without disclosing sensitive financial data (Hallak, Assaker, \& Connor, 2014). On the other hand, objective measures are financial measures that capture 
quantifiable indices of growth and success such as sales revenue growth, operating profit margin, and return on asset. Entrepreneurial performance has also been measured using successes in product and process innovation (Egan, Hunt, Kerr, \& Kolko, 2013; Wiklund \& Shepherd, 2005). Chandler and Hanks (1994) add that financial measures are typically items related to financial accounts found in the entrepreneurial profit and loss statement or balance sheet. On the other hand, nonfinancial measures are qualitative measures usually not found in the financial books of an enterprise such as customer loyalty, satisfaction, customer endorsement, or referral. However, the objective measure is inundated with the challenge of "item non-response" and even "questionnaire non-response" and business owners' reluctance in revealing financial information (Hallak et al., 2014). The subjective measures are commonly used in business research (Hallak et al., 2014; Sabharwal, 2014; Sarkar, Echambadi, \& Harrison, 2001; Wiklund \& Shepherd, 2003, 2005). Accordingly, following Choi and Rainey (2010) and in line with the objective of this study, we measure entrepreneurial performance using survey questions about the quality of work, organizational culture, managerial capability, and job-relevant resources and skills.

\section{Research methodology}

\subsection{Sample and data collection}

This research adopts a positivist approach of a survey design by using a questionnaire instrument to elicit responses from employees in entrepreneurial firms from Southeast, Nigeria. The target population of this study consists of managers, supervisors, team leaders, and workers in various departments and units of small to medium constructions and auto servicing firms in Nigeria. We were interested in firms that employ people with specific skills or craft acquired through practical training. The rationale for the small to medium size construction and auto servicing firms was on the prevalence of workers of diverse ethnicity and inter-firm alliances among companies operating within these sectors. The population of companies of interest cannot be stated with exactitude due to the absence of adequate data. Hence, it is unknown. However, to test the hypotheses, we used judgmental sampling techniques to collect data from 110 respondents. We arrived at our sample size using the $\mathrm{G}^{*}$ power analysis for multiple regression analysis, with a medium effect size of 0.15 , an $\alpha$ error probability of $0.05,0.95$ power, 3 predictors, and a 2 degree of freedom. Most of the firms surveyed have less than 50 employees. Due to resource constraints, we purposively interviewed at least a supervisor and 4 employees from about 18 SMEs in Southeast Nigeria. Data were collected between May and June 2019 using trained interviewers who were mainly postgraduate students. The respondents were interviewed in their factories during working hours from Monday to Saturday. A total of 95 copies of the questionnaire were completed and returned valid, representing a response rate of $86 \%$. The respondents consist of supervisors, entrepreneurs, and front-line employees and contract staff.

\subsection{Measures}

The instrument for data collection consists of 4 items measuring the dependent variable of entrepreneurial performance adapted from Choi and Rainey (2010). The independent variables consist of 13-items, measuring collaborative entrepreneurship adopted from Razazadeh and Nobari (2018), Diaz-Foncea and Marcuello (2013), and Franco and Haase (2013); and 5-items measuring diversity management adapted from Choi and Rainey (2010), and Magoshi and Chang (2009). All the items were measured on a seven-point Likert scale, ranging from $1=$ "Strongly Disagree" to, 7 = "Strongly Agree". The instrument was validated using content validity. Content validity refers to the extent to which items in a questionnaire are representative of the entire theoretical construct the questionnaire is designed to assess. Specifically for this study, subject-matter experts including senior academics in entrepreneurship, management, and psychology provided feedback on the extent each question measures the construct in the questions. Based on their feedback the instrument was subsequently recalibrated and revised for data collection.

\section{Result and discussion}

The demographic profile of the respondents showed that more than half of the respondents are in their early thirties and below, and about $40 \%$ are less than 45 years old; about a $40 \%$ have worked for 
either less than 5 years or between 5 to 10 years respectively. Only a few (14\%) have worked for than 15 years. The majority of the respondents (31\% with B.Sc./HND and $22 \%$ with OND/NCE) have a higher education qualification and about $30 \%$ have a senior school certificate. The ethnic composition of the respondents is made up of mostly the Igbos (62\%) and followed by the Yorubas (17\%). The empirical setting of the research in southeast Nigeria explains why the Igbos dominate the ethnic composition of the respondents. The firms surveyed were mostly between 11 to 20 years $(58 \%)$ or more than 35 years (19\%), and with a workforce size of 11 to $50(44 \%)$ workers, and or less than $10(33 \%)$ workers respectively. Table 1 shows the demographic profile of the respondents.

Table 1. Respondents' demographic profile

\begin{tabular}{|c|c|c|c|c|c|}
\hline & & Frequency & Valid Percent & Mean & S.D \\
\hline \multirow[t]{4}{*}{ Age } & $<35$ & 50 & 53.2 & & \\
\hline & $35-45$ & 36 & 38.3 & & \\
\hline & $>45$ & 9 & 8.5 & & \\
\hline & Total & 95 & 100.0 & 1.55 & .65 \\
\hline \multirow[t]{5}{*}{ Working experience } & $<5 \mathrm{yrs}$ & 37 & 38.9 & & \\
\hline & $5-10 \mathrm{yrs}$ & 37 & 38.9 & & \\
\hline & $11-15 y r s$ & 8 & 8.4 & & \\
\hline & $>15 \mathrm{yrs}$ & 13 & 14.1 & & \\
\hline & Total & 95 & 100.0 & 1.87 & .96 \\
\hline \multirow[t]{6}{*}{ Highest qualification } & FSLC & 7 & 7.3 & & \\
\hline & SSCE & 28 & 29.4 & & \\
\hline & OND/NCE & 22 & 23.2 & & \\
\hline & BSc/HND & 30 & 31.5 & & \\
\hline & Masters & 8 & 8.6 & & \\
\hline & Total & 95 & 100.0 & 3.13 & 1.06 \\
\hline \multirow[t]{5}{*}{ Ethnicity } & Hausa & 12 & 12.6 & & \\
\hline & Yoruba & 17 & 17.8 & & \\
\hline & Igbo & 62 & 65.4 & & \\
\hline & Others & 4 & 4.2 & & \\
\hline & Total & 95 & 100.0 & 2.72 & .66 \\
\hline \multirow[t]{5}{*}{ Firm Size } & $<10$ workers & 31 & 32.6 & & \\
\hline & $11-50$ workers & 44 & 46.3 & & \\
\hline & $51-100$ & 6 & 6.3 & & \\
\hline & $>100$ & 14 & 14.7 & & \\
\hline & Total & 95 & 100.0 & 2.09 & 1.02 \\
\hline \multirow[t]{5}{*}{ Firm age } & $<10 \mathrm{yrs}$ & 13 & 13.7 & & \\
\hline & 11-20yrs & 55 & 57.9 & & \\
\hline & $21-35 \mathrm{yrs}$ & 9 & 9.5 & & \\
\hline & $>35 \mathrm{yrs}$ & 18 & 18.9 & & \\
\hline & Total & 95 & 100.0 & 2.36 & .96 \\
\hline
\end{tabular}

\subsection{Factor Analysis}

A factor analysis was performed on the data set using varimax rotation and eigenvalue set at 1 . Factor loadings below 0.5 were cut-off, and items with cross-loading deleted from the measure. The factors account for $66 \%$ of the total variance explained. Factor 1 consists of 5 -items measuring the dependent variable entrepreneurial performance and accounts for $45 \%$ of the explained variance. Diversity management loaded in factor 2 consisting of 4 -items and accounts for $9 \%$ of the explained variance, with the item such as "every team member, gets their accurate salary regularly irrespective of their ethnicity" cross-loaded and was therefore deleted. External collaboration loaded on factor 3 with 5items accounting for $7 \%$ of the explained variance. Two-items "We develop a network of relationships with other external organizations who have better-specialized competencies and skills", 
and "There is proactive communication with external partners about how to manage joint activities" were also deleted for cross-loading. Finally, 3-items relating to the internal collaboration factor, accounting for $5 \%$ of the explained variance loaded on the fourth factor and labelled accordingly. Cronbach's alpha was computed to measure the internal reliability of the factors. All factors had internal reliability between .78 and $.85(\alpha>.70$; Nunally, 1978). The factor loadings, variance explained, and reliability results are presented in Table 2 .

Table 2. Factor analysis, reliability test and explained variance

\begin{tabular}{lc}
\hline & 1 \\
\hline Entrepreneurial Performance & .78 \\
The skill level in my work unit has improved in the past year. & .77 \\
Overall, we are able to meet our customer needs faster & .69 \\
The overall quality of work done by our work team is excellent & .69 \\
Our workforce has the job-relevant knowledge and skills necessary to & .65 \\
achieve organizational goals. & \\
Overall, my immediate supervisor/team leader is doing a good job &
\end{tabular}

Supervisors/team-leaders in my work unit are committed to a workforce representative of different ethnic groups

.81

.80

.52

\section{External Collaboration}

In our work team, there is mutual and balanced resource sharing among team members

Our work teams are usually proactive in meeting market/customers? needs

We trust our external partners to give priority to joint issues

Our work teams are able to notice and exploit new businesses or entrepreneurial opportunities before competitors

\section{Internal collaboration}

There is usually collective decision-making through team projects comprising all members of the team

We experience effective flow of information and knowledge among team members

Everyone in our team is open to creative/ innovative ideas in collective projects

\section{Cronbach alpha \\ Explained variance \\ Extraction Method: Principal Component Analysis. Rotation Method: Varimax with Kaiser Normalization. \\ Rotation converged in 7 iterations.}

\subsection{Hypotheses testing}

The hypotheses were tested using a multiple regression analysis through SPSS version 15 . The regression result shows a good model fit $F_{3,91}=10.25$, and accounts for $25 \%$ of the variation in the dependent variable. $\mathrm{H} 1$ tested the effect of internal collaboration on entrepreneurial performance. The 
result shows a statistically non-significant effect for internal collaboration on entrepreneurial performance $(\beta=.03, \mathrm{p}=0.77)$. Therefore, our dataset does not support H1. However, external collaboration shows a statistically significant effect on entrepreneurial performance $(\beta=.25, p<$ 0.05). Similarly, diversity management shows a statistically significant effect on entrepreneurial performance $(\beta=.32, \mathrm{p}<0.05)$. The regression result further shows that diversity management had the most influence on entrepreneurial performance. Further, we test for the effect of diversity management on collaborative entrepreneurship and find a positive and statistically significant effect $(\beta=.36, \mathrm{p}<0.05)$. The regression result is presented in table 3 below.

Table 3. Regression result

\begin{tabular}{|c|c|c|c|c|c|c|}
\hline \multirow[b]{2}{*}{ Mode } & & \multicolumn{2}{|c|}{ Unstandardized Coefficients } & \multirow{2}{*}{$\begin{array}{c}\text { Standardized } \\
\text { Coefficients }\end{array}$} & \multirow[b]{2}{*}{$\mathrm{t}$} & \multirow[b]{2}{*}{ Sig. } \\
\hline & & $\mathrm{B}$ & Std. Error & & & \\
\hline \multirow[t]{4}{*}{1} & $(\text { Constant })^{\mathrm{a}}$ & 3.567 & .514 & & 6.939 & .000 \\
\hline & Internal collaboration & .022 & .074 & .029 & .294 & .769 \\
\hline & External collaboration & .194 & .076 & .251 & 2.562 & .012 \\
\hline & Diversity management & .259 & .085 & .317 & 3.057 & .003 \\
\hline \multirow[t]{2}{*}{2} & $(\text { Constant })^{\mathrm{b}}$ & 2.942 & .645 & & 4.562 & .000 \\
\hline & Diversity management & .394 & .117 & .360 & 3.367 & .001 \\
\hline
\end{tabular}

Dependent Variable: a. Entrepreneurial performance, b. Collaborative entrepreneurship

\subsection{Discussion}

The purpose of this study was to investigate the extent diversity management practices, and the collaborative entrepreneurship within and among entrepreneurial firms affect entrepreneurial performance. The result shows that external collaboration among firms enhances entrepreneurial performance. In order words, when external partners collaborate by leveraging resources to exploit opportunities, the overall quality of the output increases collectively, and customers' needs met faster and better. Also, entrepreneurial performance improves when external partners engage in mutual and balanced resource sharing, and proactively spot market opportunities faster than competitors. This finding supports Rezazzadeh and Nobari (2018) who found a predominant significant path coefficient between inter-firm collaboration and performance (i.e., innovation and sensing capability) and Sarkar et al. (2001) who also found a strong effect for alliance proactiveness on firm performance but contradicts previous findings by Lassen et al. (2008), who found a non-significant effect for external collaboration on the radicality of innovation projects.

Surprisingly, our result shows an insignificant effect on internal collaboration and entrepreneurial performance. This finding is consistent with Lassen et al. (2008) who found a significant and negative effect for broad internal collaboration on firm's innovativeness but contradicts Yan and Sorenson (2006) positive and significant finding for collaboration and collective entrepreneurship for a family business, and Middel (2008) who reported the importance of internal collaboration on innovative performance. We had expected that internal collaboration among work teams to improve entrepreneurial performance. Our assumptions are based on that work teams jointly work on a specific task to meet customers' demands. A plausible explanation for this finding is that the workers in most of the firms surveyed work on contractual bases. Hence, they are paid based on the level of their productivity rather than group performance. Another reason is that the task performed in the firms surveyed require low-task performance (the type of skill that requires practical training) with limited cognitive processing and problem-solving activity. Though we did not test for task-complexity, a potential limitation of the study, we suspect that it might explain the non-significant effect of this relationship. Where extensive cognitive processing is required, such as a high-task performance, the managers or entrepreneurial owners often solve the problem alone or collaborate externally with strategic partners to solve such problems. However, since internal collaboration contributes to the 
model, it is sufficing to say that firm performance improves when internal work teams are involved in projects and, there is a free flow of information, knowledge, and resource sharing.

The results also reveal that diversity management influences entrepreneurial performance. Diversity management practices that attempt to relegate social categorization in the workplace by encouraging inclusion and equal opportunity for all significantly predict entrepreneurial performance. Thus, entrepreneurial firms that recruit, train, and mentor people with different ethnic skills promote and pay them equally, and encourage social cohesion would harness the productivity and performance of these employees. This finding corroborates earlier finding by Cooke and Saini (2010) and Choi and Rainey, (2010), who reported significant positive effect for diversity management on firm performance; Boone et al. (2018), who found a significant effect for nationality diverse top management team on innovation performance, and Magoshi and Chang (2009) who found a positive and significant relationship between diversity management and organizational commitment. However, the findings contradict Kochan et al.'s finding who found a non-significant effect for racial diversity on organizational performance and Chatman and Flynn (2001) who found a non-significant effect between diversity and organizational performance.

Finally, the result shows a significant effect on diversity management and collaborative entrepreneurship. In order words, having a work team consisting of members of different ethnic groups enhances the creation of something of economic value through the sharing of information and knowledge that transpire among work teams. This finding gives credence to the assertion that diversity based on the cultural or ethnic background is a strong predictor of entrepreneurship and lend support to McLeod et al. (1996) who found that a diverse workgroup produces better creative performance than homogeneous workgroups. The finding also supports Rodríguez-pose and Hardy $\underline{(2015)}$ who found a significant relationship between cultural diversity and entrepreneurship and Cox and Blake (1991) who asserts that the insights brought by work-teams with varying ethnic backgrounds helped companies reach a variety of markets. More importantly, diversity breeds collaborative entrepreneurship when the work-teams perceive deliberate efforts to train, mentor, and promote people in the workplace irrespective of their ethnic background.

\section{Conclusion}

This study explored the extent to which diversity management and collaborative entrepreneurship affect entrepreneurial performance. And it also examined ethnic-diversity effects on collaborative entrepreneurship. Through a regression analysis with a significant value of less than 5 percent $(\mathrm{p}<$ .05 ), we conclude that it is the collaborative relationship that exists between or among external partners, rather than the internal collaboration among employees or workgroups that improves firms' performance. Performance improves when entrepreneurial firms collaborate with other firms with complementary resources, and by so doing, harness the cognitive resources of their work teams, to proactively exploit market opportunities, and efficiently produce goods and services to meet market needs. The result suggests that internal collaboration in work teams with diverse ethnic skills may not improve entrepreneurial performance, especially for exploiting market innovations. However, managing the ethnic diversity of a workforce promotes collaborative entrepreneurship. Workforce diversity is a source of competitive advantage for entrepreneurial firms when effectively managed. Entrepreneurship behaviour ensues when firms recognize the different ethnic backgrounds of its workforce and strategically manage their diversity to achieve their objectives.

The findings have some implications for practice. First, the finding implies that since most entrepreneurial businesses face resource scarcity, it is important for firms to collaborate with external partners to harness resources for organizational performance. These firms can partner with complementary firms to provide prompt and efficient services to customers, exploit new market opportunities, and even innovate. For instance, an auto panel-beating repair firm can partner with a car-bumper repair firm and or an auto mechanic to provide auto-revamp services. All the parties collaboratively provide service to customers more efficiently than when they operate competitively. Second, though internal collaboration may not improve performance in terms of exploiting new markets, however, the task complexity and the cognitive requirement of a job may require having a 
culturally diverse workforce. Third, firms can achieve organizational success when diversity is strategically managed. In order words, managers need to strategically recruit and retain employees from different ethnic backgrounds to harness their varied skills, knowledge, and ideas. The variety of skills, knowledge, and ideas these crop of workers bring is a critical firm's resources necessary for sustaining competitive advantage and exploiting entrepreneurial opportunities. Finally, when a firm's workforce consists of people from diverse ethnicity, collaborative entrepreneurship may ensue only when the work environment is devoid of discrimination and social categorization. Having a robust diversity management program would be beneficial in this respect.

\section{Limitations and suggestion for further studies}

This study investigated collaborative entrepreneurship, diversity management, and firm performance, and found that diversity drives collaborative entrepreneurship. The limitations of the study include first, the inability to collect data from all the major cosmopolitan cities in Nigeria where a larger pool of ethnically diverse workforce resides limit the generalizability of the findings. There is a need to conduct further studies across major cosmopolitan cities with larger sample size and probably in other sectors such as services firms and high-tech firms. Second, we examined workforce diversity based on ethnic skill on the assumption that people from some ethnic background are perceived to have better competencies in performing certain tasks. However, we did not control for the education of the respondents. Third, the interview was self-reported; therefore, there is a tendency for respondents to provide a socially desirable response, which may impair the relationships among variables. We believe that this may affect the relationships reported in this study. Finally, we tested our assumptions using regression analysis. Future studies may use more robust statistical techniques such as path analysis or structural equation modeling and test for the moderating or mediating effects of diversity management on collaborative entrepreneurship and firms' performance.

\section{Acknowledgment}

The authors acknowledge Prof. A.D. Nkamnebe, Dr. T.C. Okeke, Dr. O.A.U. Nnedum, and the anonymous reviewers for the insights provided in enriching this work. Any financial or nonfinancial support for the study should be acknowledged.

\section{References}

Ahuja, G. (2000). The duality of collaboration: inducements and opportunities in the formation of inter-firm linkages. Strategic Management Journal, 21, 317-343.

Alvarez, S., \& Busenitz, L. W. (2001). The entrepreneurship of resource-based theory. Journal of Management, 27(June), 755-775. https://doi.org/10.1177/014920630102700609.

Andresen, E., Lundberg, H., \& Wincent, J. (2014). Processes in collaborative entrepreneurship: a longitudinal case study of how multiple actors exploit a radically new opportunity. Int. Entrep. Manag $J, 10,713-726$.

Ayub, N., \& Jehn, K. A. (2018). Exploring diversity effects: nationality composition and nationality context in workgroups. European Journal of Work and Organizational Psychology, 27(5), 616628.

Barnes-Mauthe, M., Arita, S., Allen, S. D., Gray, S. A., \& Leung, P. (2013). The influence of ethnic diversity on social network structure in a common-pool resource system: implications for collaborative. Ecology and Society, 18(1), 1-13.

Bassett-Jones, N. (2005). The paradox of diversity management, creativity and innovation. Creativity and Innovation Management, 14(2), 169-175.

Boone, C., Lokshin, B., Guenter, H., \& Belderbos, R. (2018). Top management team nationality diversity, corporate entrepreneurship and innovation in multinational firms. Strategic Management Journal, 40(2), 277-302.

Chandler, G.N., \& Hanks, S.H. (1994). Market attractiveness, resource-based capabilities, venture strategies, and venture performance. Journal of Business Venturing, 9(4), 331-349.

Chatman, J. A., \& Flynn, F. J. (2001). The influence of demographic heterogeneity on the emergence and consequences of cooperative norms in work teams. Academy of Management Journal, 44, 956-974. 
Choi, S., \& Rainey, H. G. (2010). Managing diversity in U.S. federal agencies: effects of diversity and diversity management on employee perceptions of organizational performance. Public Administration Review, 70(1), 109-121.

Cooke, F. L., \& Saini, D. S. (2010). Diversity management in India: a study of organizations in different ownership forms and industrial sectors. Human Resource Management, 49(3), 477500 .

Cox, T. H., \& Blake, S. (1991). Managing cultural diversity: implications for organizational competitiveness. Academy of Management Executive, 5(3), 45-56.

Diaz-Foncea, M. \& Marcuello, C. (2013). Entrepreneurs and the context of cooperative organizations: a definition of cooperative entrepreneur. Canad. Journal of Adm. Sc., 30(4), 238-251.

Egan, T., Hunt, J., Kerr, B., \& Kolko, J. (2013). Cultural Diversity, Innovation, and Entrepreneurship: Firm- $\quad$ level Evidence from London. Economic Geography, 89(4), 367-394.

Ely, R. J., \& Thomas, D. A. (2001). Cultural diversity at work: the effects of diversity perspectives on work group processes and outcomes. Administrative Science Quarterly, 46, 229-273.

Emejulu, G.E., Agbasi, O.A., Nosike, C. (2020). Strategic agility and performance of small and medium enterprises in the phase of COVID-19 pandemic. International Journal of Financial, Accounting, and Management, 21(1), 41-50.

Filion, L.J. (1999). Entrepreneurship: entrepreneurs and owner-managers of small businesses. Revista de Administracao, 34(1), 5-28.

Franco, M, Haase, H. (2013). Firm resources and entrepreneurial orientation as determinants for collaborative entrepreneurship. Management Decision, 51(3), 680-696.

Franco, M., \& Pessoa, N. (2014). University sports partnerships as collaborative entrepreneurship: an exploratory case Study. Administration \& Society, 46(8), 885- 907.

Friberg, J. H., \& Midtbøen, A. H. (2018). Ethnicity as skill: immigrant employment hierarchies in Norwegian low-wage labour markets. Journal of Ethnic and Mig. Studies, 44(9), 1463-1478.

Galaskiewicz, J. and A. Zaheer (1999). Networks of competitive advantage. Research in the Sociology of Organizations, 16, 237-261.

Hallak, R., Assaker, G., \& Connor, P. O. (2014). Are family and nonfamily tourism businesses different? An examination of the entrepreneurial self-efficacy entrepreneurial performance relationship. Journal of Hospitality and Tourism Research, 38, 388-413. https://doi.org/10.1177/1096348012461545.

Hayton, J. C. (2003). Strategic human capital management in SME: An empirical study of entrepreneurial performance. Human Resource Management, 42(4), 375-391. https://doi.org/10.1002/hrm.10096.

Horwitz, S. K., \& Horwitz, I. B. (2007). The effects of team diversity on team outcomes: a metaanalytic review of team demography. Journal of Management, 33(6), 987-1015.

Kochan, T., Bezrukova, K., Ely, R., Jackson, S., Joshi, A., Jehn, K., ... Levine, D. (2003). The effects of diversity on business performance: report of the diversity research network. Human Resource Management, 42(1), 3-21. https://doi.org/10.1002/hrm.10061.

Kossek, E.E. \& Lobel, S.A. (eds.) (1996). Managing diversity: human resource strategies for transforming the workplace. Blackwell, Cambridge, MA.

Kusa, R. (2017). Interorganisational collaboration in view of the theory of entrepreneurship. Studiai Materialy, 2017(23), 83-93. https://doi.org/10.7172/1733-9758.2017.23.8

Lassen, A. H., Laugen, B. T., \& Middel, R. (2008). Collaborative entrepreneurship: on the influence of internal and external collaboration on corporate entrepreneurial innovation. 9th international CINET conference: radical challenges in innovation management publication, 530-543. Aalborg University, Denmark: Continuous Innovation Network.

Latimer, R.L. (1998). The case for diversity in global business, and the impact of diversity on team performance, Competitiveness Review; Indiana. 8(2), 3-17.

Lumpkin, G.T., \& Dess, G.G. (1996). Clarifying the entrepreneurial orientation construct and linking it to performance. Academy of Management Review, 21(1), 135-72.

Magoshi, E., \& Chang, E. (2009). Diversity management and the effects on employees' organizational commitment: Evidence from Japan and Korea. Journal of World Business 44, 31-40.

McLeod, P. L., Lobel, S. A., \& Cox, T. H. (1996). Ethnic diversity and creativity in small groups. Small Group Research, 27(2), 248-264. 
Middel, H. (2008). Collaborative Improvement: action learning in the extended manufacturing enterprise. An action learning approach, $\mathrm{PhD}$ thesis, University of Enschede.

Miner, A. S., T. L. Amburgey and T. M. Stearns (1990). Interorganizational linkages and population dynamics: Buffering and transformational shields. Administrative Science Quarterly, 35(4), $689-713$.

Naude, W., Szirmai, A. \& Guedhuys, M. (2011). Innovation and entrepreneurship in developing countries, $\quad$ Policy Brief No. 1, United Nation's University, Helsinki, Finland.

Nielsen, A. P. (2006). Understanding dynamic capabilities through knowledge management. Journal of Knowledge Management, 10(4), 59-71. https://doi.org/10.1108/13673270610679363.

Nnoli, O. (1995). Ethnicity and development in Nigeria. Aldershot: Avebury.

Nunally, J.C. (1978). Psychometric Theory. New York, NY: McGraw-Hill.

Nyambegera, S. M. (2002). Ethnicity and human resource management practice in sub-Saharan Africa: the relevance of the managing diversity discourse. The International Journal of Human Resource Management, 13(7), 1077-1090.

Obi, C.I. (2001). The changing forms of identity politics in Nigeria under economic adjustment: the case of the oil minorities' movement of the Niger Delta. (No. 119), Nordic Africa Institute.

Olsen, J. E., \& Martins, L. L. (2012). Understanding organizational diversity management programs: a theoretical framework and directions for future research. Journal of Organizational Behavior, 33(8), $\quad 1168-1187$.

Pinho, J. C., \& De Sa, E. S. (2014). Personal characteristics, business relationships and entrepreneurial performance: Some empirical evidence. Journal of Small Business and Enterprise Development, 21(2), 284-300. https://doi.org/10.1108/JSBED-10-2013-0150.

Pitts, D. W. (2009). Diversity, representation, and performance: evidence about race and ethnicity in public organizations. Journal of Public Administration Research and Theory, 15(4), 615-631.

Ratten, V. (2014). Future research directions for collective entrepreneurship in developing countries: a small and medium-sized enterprise perspective. Int. J. Entrepreneurship and Small Business, 22(2), 266-274.

Ratten, V., \& Ratten, V. (2014). Encouraging collaborative entrepreneurship in developing countries : the current challenges and a research agenda. Journal of Entrepreneurship in Emerging Economies, 6(3), 298-308.

Rezazadeh, A., \& Nobari, N. (2018). Antecedents and consequences of cooperative entrepreneurship: a conceptual model and empirical investigation. Int. Entrep. Manag J., 14, 479-507.

Ribeiro-Soriano, D. \& Urbano, D. (2009). Overview of collaborative entrepreneurship: an integrated approach between business decisions and negotiations. Group Decision and Negotiation, 18(5), 419-430.

Rodríguez-pose, A., \& Hardy, D. (2015). Cultural diversity and entrepreneurship in England and Wales. Environment and Planning A, 47, 392-411.

Roundy, P. T., \& Fayard, D. (2018). Dynamic capabilities and entrepreneurial ecosystems: The micro- foundations of regional entrepreneurship. The Journal of Entrepreneurship, 1-27.

Sabharwal, M. (2014). Is diversity management sufficient? Organizational inclusion to further performance. Public Personnel Management, 43 (2), 1-21.

Sarkar, M. B., Echambadi, R. A. J., \& Harrison, J. S. (2001). Alliance entrepreneurship and firm market performance. Strategic Management Journal, 22, 701-711. https://doi.org/10.1002/smj.179.

Sebikari, K. V. (2019). Entrepreneurial performance and small business enterprises in Uganda. Int. Journal of Social Sciences Management and Entrepreneurship, 3(1), 162-170.

Shane, S. \& Venkataraman, S. (2000). The promise of entrepreneurship as a field of research. Academy of Management Review, 25(1), 217-225.

Stevenson, H.H. \& Jarillo, J.C. (1990). A Paradigm of entrepreneurship: entrepreneurial management. Strategic Management Journal, 11(4), 17-27.

Teece, D. and Pisano, G. (1994). The dynamic capabilities of firms: an introduction. Industrial and Corporate Change, 3 (3), 537-56. 
Teece, D. J. (2014). A dynamic capabilities-based entrepreneurial theory of the multinational enterprise. Journal of International Business Studies, 45, 8-37. https://doi.org/10.1057/jibs.2013.54.

Teece, D. J., (2007). Explicating dynamic capabilities: The nature and micro-foundations of (sustainable) enterprise performance. Strategic Management Journal, 28(13), 1319-1350.

Teece, D. J., Pisano, C., \& Shuen, A., (1997). Dynamic capabilities and strategic management. Strategic Management Journal, 18, 509-533.

Umenzinwa, C. (2012). Ethnicity and Nigeria's underdevelopment. Ogirisi: A New Journal of African Studies, 9, 215-229.

van Knippenberg, D., De Dreu, C. K. W., \& Homan, A. C. (2004). Work group diversity and group performance: An integrative model and research agenda. Journal of Applied Psychology, 89, $1008-1022$.

Wang, J., Cheng, G. H. L., Chen, T., \& Leung, K. (2019). Team creativity/innovation in culturally diverse teams : A Meta-Analysis. Journal of Organizational Behavior, 40(6), 693-708.

Wernerfelt, B. (1984). A resource-based view of the firm. Strategic Management Journal 5(2), 171180.

Wiklund, J., \& Shepherd, D. (2003). Knowledge-based resources, entrepreneurial orientation, and the performance of small and medium-sized businesses. Strategic Management Journal, 24, 13071314. https://doi.org/10.1002/smj.360.

Wiklund, J., \& Shepherd, D. (2005). Entrepreneurial orientation and small business performance: A configurational approach. Journal of Business Venturing, 20, 71-91. https://doi.org/10.1016/j.jbusvent.2004.01.001.

Yan, J., \& Sorenson, R. L. (2006). Collective entrepreneurship in family firms: the influence of leader attitudes and behaviors. New England Journal of Entrepreneurship, 6(2), 37- 51.

Yang, Y., \& Konrad, A. M. (2011). Understanding diversity management practices: implications of institutional theory and resource-based theory. Group \& Organization Management, 36(1), 638. https://doi.org/10.1177/1059601110390997. 